\title{
Derecho o Economía en la Equidad Fiscal $^{* *}$ Law or Economy related to Fiscal Equity
}

\section{Resumen}

El debate jurídico sobre equidad fiscal sigue vigente. A pesar de la claridad en relación con los principios de equidad horizontal y vertical, permanece la discusión en cuanto a la definición de qué es una situación fiscal igualitaria medida en relación con los conceptos de proporcionalidad y progresividad. La hipótesis señala que el Derecho Público no ha sido capaz de distinguir y clarificar los anteriores conceptos e, inclusive, los llega a interpretar en forma similar. El estudio se basa en contrastar el marco teórico apoyado en conceptos económicos, evidencia empírica del sistema fiscal en México y el análisis constitucional para demostrar los problemas jurídicos que existen. Los resultados demuestran que el Derecho vigente no ha sido capaz de diferenciar o utilizar la progresividad de las tasas como elemento fundamental para discernir la equidad fiscal, tal y como sucede en los análisis económicos.

\section{Palabras clave}

Administración pública - derecho público - finanzas públicas.

* Profesor Tiempo Completo, Universidad Autónoma de Querétaro, Ph.D. in Public Affairs, Indiana University, erabell@mail.com

\begin{abstract}
The legal discussion over fiscal equity still is an important issue. Despite the comprehensible principles related to horizontal and vertical equity, the argument about what is a similar fiscal situation measured by the concepts of proportionality and progressivity remains present. The hypothesis mentions that the Public Law has not been able to distinguish and explain the latter concepts, and sometimes, both are interpreted in the same way. The study is based on confronting the theoretical part sustained on economic notions, empirical evidence related to the Mexican fiscal system and, the constitutional study in order to demonstrate the current law problems. The results show that the positive Law

** Artículo recibido el 31 de agosto de 2016 y aceptado para su publicación el 26 de octubre de 2016.
\end{abstract}


system has not been able to differentiate or apply the concept of tax rate progressivity as a fundamental issue to consider fiscal equity, as it happens within the economic analyses.

\section{Key words}

Public administration - public law - public finance.

\section{El problema de la justicia fiscal}

Aunque es indiscutible los avances del Derecho, en particular por medio de las jurisprudencias, sobre el concepto y dimensión de la justicia fiscal, sigue siendo una tarea pendiente el definir en forma clara postulados genéricos derivados de los principios de igualdad horizontal y vertical, tales como qué es ser igual desde el punto de vista fiscal, capacidad económica, proporcionalidad, entre otros aspectos que son fundamentales para tener una certeza absoluta sobre si un impuesto o ingreso público es justo y equitativo.

El presente estudio tiene por finalidad confrontar los principios jurídicos más reconocidos en el ámbito de la equidad fiscal, frente a principios filosóficos, de Economía y Finanzas Públicas, para acreditar que diversos conceptos jurídicos, en particular el de "proporcionalidad", no tienen congruencia al poder ser interpretados de diversas formas, y por ende, no tienen la claridad que ayude a resolver estas cuestiones en forma consistente a través del tiempo. Situación que se manifiesta en forma más evidente en relación con los impuestos sobre rentas y ventas.

Por tanto, la hipótesis del presente trabajo consiste en señalar que los criterios de Derecho Público, utilizados para definir el concepto de equidad fiscal, son obsoletos y permiten diversas formas de interpretación que en vez de ayudar, alejan al sistema fiscal de una congruencia basada ya sea en principios de equidad o de eficiencia según sea el caso. Con la finalidad de contestar dicha hipótesis el estudio utiliza la deducción como metodología principal. Esto es, deducir a partir de una serie de principios filosóficos aplicados desde una perspectiva económica, los principios técnicos, en particular las definiciones económicas de regresividad, proporcionalidad y progresividad, más aceptados en materia fiscal. Los cuales serán utilizados para contrastarlos frente a los principios más aceptados del Derecho Fiscal, así como referencias empíricas relativas a la equidad.

En ese orden de ideas se presentan los siguientes apartados. El segundo relativo a la discusión sobre la diferencia entre equidad y eficiencia fiscal, presentando los conceptos de progresividad, proporcionalidad y regresividad. El siguiente analiza los principios fiscales relativos a los criterios básicos que tienen por finalidad crear los instrumentos para repartir las cargas fiscales, desde aspectos de los beneficios recibidos, ingresos, gastos o consideración del patrimonio. El apartado cuarto describe el análisis constitucional y legal en México relativo a los conceptos de equidad fiscal, centrados sobre el término de proporcionalidad. El quinto contiene un breve estudio de Derecho comparado, en 
particular de países en Latinoamérica, en el cual se acredita desarrollos jurídicos similares a México. El apartado sexto estudia en forma empírica tanto los antecedentes fiscales en México como la situación actual. Y, para concluir, el apartado séptimo presenta las conclusiones en las cuales se desarrollan las consecuencias entre el desarrollo teórico con base en principios económicos, los resultados empíricos, así como los problemas jurídicos encontrados, concluyendo con la necesidad de adecuar la Constitución y legislación en la materia si la finalidad es tener congruencia ya sea con la eficiencia o equidad como principios rectores del sistema fiscal.

\section{Marco conceptual}

El desarrollo de conceptos técnicos claros y puntuales es fundamental para analizar las consecuencias del diseño o efecto de un impuesto, así como el conjunto del sistema fiscal, sobre cuestiones de eficiencia y equidad, para con ello verificar las implicaciones sobre ética y justicia. El primer aspecto corresponde a los principios generales o dilema entre eficiencia y equidad; y la segunda parte teórica corresponde a los retos sobre las técnicas o formas para medir dichas cuestiones.

Una carga impositiva presenta aspectos de eficiencia y equidad en cuanto a su diseño y consecuencias. Aunque ambas cuestiones están unidas, su estudio separado permite un análisis puntual. En cuanto a la eficiencia, un impuesto presenta dos efectos: primero al reducir el patrimonio del consumidor como una transferencia de recursos al gobierno; y segundo, en forma indirecta, como un aumento en los precios de los bienes grabados frente a los bienes que no lo están; esta última situación no se presenta en el caso de una carga general individual, ya que no hay impuesto a ningún bien. El primer aspecto produce un efecto sobre el ingreso, mientras que el segundo además ocasiona un efecto de substitución sobre bienes derivado del cambio de precios.

En principio un impuesto es ineficiente cuando presenta una reducción del patrimonio del consumidor derivado del pago del impuesto; situación que se conoce también como carga excesiva del impuesto. En particular la carga excesiva es consecuencia del cambio inducido por el impuesto o distorsión de precios entre bienes grabados y bienes sin impuestos. Por tanto, una carga individual impositiva, no atada al consumo, la cual por definición no introduce cambios en los precios de los bienes, no tiene ninguna carga excesiva o perdida de eficiencia. De esta forma, la carga excesiva de un impuesto es la diferencia entre la pérdida adicional de patrimonio frente a una carga individual impositiva de la misma tasa fiscal. Además, si un impuesto se establece sobre todos los bienes y a la misma tasa fiscal, no habrá carga excesiva o pérdida fiscal ${ }^{1}$.

Esta situación nos llevaría a dos opciones para tener un sistema fiscal totalmente eficiente. Por un lado la posibilidad de establecer un solo impuesto individual no atado a ninguna

Auerbach (1985), pp. 61-127. 
transacción económica. Y, como segunda opción, un impuesto dirigido al consumo pero con la condición de que todos los bienes y servicios de la economía estuvieran grabados a la misma tasa ${ }^{2}$. Sin embargo, esta eficiencia pudiera estar lejos de valores de equidad conforme a los principios que vamos a ver a continuación.

Por el otro lado, la equidad se refiere a igualdad, la cual implica valores éticos, morales y culturales. Partiendo del concepto clásico de tratar igual a los iguales y desigual a los desiguales, Musgrave desarrolló los conceptos de igualdad horizontal, referida a dar el mismo tratamiento fiscal a personas que se encuentran en la misma situación; y el de igualdad vertical, el cual señala que es necesario dar un tratamiento fiscal desigual para personas en situaciones diferentes ${ }^{3}$. A pesar de la importancia teórica y sencillez de estos principios, sigue siendo un tema pendiente en la literatura, la política fiscal o Derecho, el definir a dos personas como iguales. Además los referidos principios no pueden ser prácticos en tanto no sean definidas las siguientes cuestiones esenciales: a) la base para definir la igualdad entre individuos; b) se defina el concepto de tratamiento fiscal igualitario; y c) se implementen principios para guiar la política fiscal ${ }^{4}$.

Esto es, la justicia horizontal se refiere al hecho de que dos personas en la misma situación fiscal, económica o financiera, deberán pagar exactamente la misma cantidad o proporción de impuestos. Conforme se desarrolla el documento se verán las implicaciones de cómo medir dicha igualdad horizontal ya que puede referirse a una transacción económica (compra/venta), una situación financiera (balance) o el patrimonio económico de las personas. La situación contraria es el principio vertical que equivale a que dos personas en situaciones económicas diferentes deberán pagar impuestos diferentes; lo cual equivale a que la persona con mayor ventaja económica pagaría más impuestos que una en una situación inferior. En este caso, dicha diferencia presenta como controversia si dicha diferencia se refiere a cantidad, porcentajes o proporciones.

Con la finalidad de poder medir y entender las consecuencias de los principios antes citados se han desarrollado los conceptos técnicos de progresividad, proporcionalidad y regresividad. Al respecto, Lobaiza señala que:

"Un impuesto es proporcional si a medida que ascendemos por la escala de ingresos (suponiendo que este sea el indicador de bienestar utilizado), la presión tributaria soportada por los agentes económicos permanece constante. Es regresivo cuando la presión tributaria decrece con el nivel de ingreso, mientras que resultará progresivo cuando aumenta". Añade como ejemplo que "si la participación de la renta del capital aumenta cuando subimos por la escala de ingresos, entonces un impuesto sobre la renta del capital tiende a ser más progresivo que un impuesto general sobre los ingresos. Análogamente, un impuesto sobre los productos de lujo tiende a ser progresivo, mientras que un impuesto sobre articulos de consumo masivo

\footnotetext{
Destaca como STIGLITZ (2002) antepone los principios de eficiencia antes que los de justicia al establecer los siguientes criterios del sistema tributario: eficiencia económica, sencillez administrativa, flexibilidad, responsabilidad política y justicia.

Musgrave (1990), pp. 113-22.

ZEE (1995), p. 30.
} 
tenderá a ser regresivo. Estas relaciones desempeñan una función clave al analizar la incidencia de diversos impuestos"s.

Por tanto, la progresividad corresponde al principio vertical, siendo equivalente a que las personas con mayor capacidad económica o financiera deberán pagar más impuestos. Ahora bien, la discusión como ya se apuntó corresponde a cómo medir dicha progresividad ya que se refiere a la cantidad a pagar, al porcentaje impositivo o como medida frente al patrimonio. En principio, podría pensarse en la cantidad y justificar que una persona rica al consumir más paga más (inclusive bajo una misma tasa impositiva los bienes). Sin embargo, desde el punto de vista microeconómico resulta evidente que no es lo mismo el sacrificio de una persona que vive con un salario mínimo al día -por ejemplo un 10\% de su consumo le puede representar dejar de comer alimentos básicos para su familia- que el sacrificio de una persona rica al pagar un mismo porcentaje en su consumo, aunque paga una mayor cantidad, en ningún momento le representará un sacrificio mayor a su consumo o economía en virtud de sus ahorros e inversiones que cuenta; o lo que representa dicho gasto o impuesto frente a su patrimonio. Las personas en las clases inferiores gastan la mayoría de sus ingresos en consumo y prácticamente no tienen ahorros y/o inversiones (o patrimonio). Por tanto su sacrificio es mayor. De ahí, que para que un impuesto sea justo o progresivo, desde esta óptica, el impuesto tiene que tener una tasa progresiva que implique mayores sacrificios en tanto se tenga mayores ingresos o recursos económicos. La consecuencia no es tanto gravar la transacción económica sino que sea justo desde la óptica del patrimonio de las personas y del sacrificio que se hace al pagar el impuesto.

Inclusive, un sistema con tasas que son muy reducidas en cuanto al rango de la progresividad no cumplirán este requisito de ser progresivas frente al patrimonio. No existe un principio general para poder señalar los rangos o escalas exactas de tasas progresivas ya que estas dependerán de la situación económica del país, el ciclo económico en general y los ingresos de las personas. Sin embargo, es claro que si las tasas del impuesto no son progresivas entonces no habrá progresividad en el sistema y no se cumplirá el principio de equidad vertical.

Los otros principios son los resultados opuestos. Si el impuesto es proporcional esto equivale a que todos, desde su perspectiva patrimonial, pagaran lo mismo sin importar su condición económica. Y regresivo cuando ocurra la situación contraria en la cual las personas de ingresos inferiores paguen más impuestos que los de una posición económicamente alta.

Otro aspecto de la progresividad está relacionado con la desigualdad de la renta. Resulta especialmente ilustrativo analizar mediante curvas de Lorenz el efecto sobre la desigualdad de un impuesto progresivo. Sean $\mathrm{L}_{\mathrm{X}} \mathrm{y} \mathrm{L}_{\mathrm{X}-\mathrm{T}}$ las curvas de Lorenz antes y después de impuestos, respectivamente. Si el impuesto es progresivo, $\mathrm{L}_{\mathrm{X}-\mathrm{T}}$ va por encima de $\mathrm{L}_{\mathrm{X}}$ (véase gráfico 1). Es decir, porcentualmente disminuye más la renta antes de impuestos de los preceptores de rentas más altas que la de los preceptores de rentas más bajas. En este caso,

LoBAIZA (2001), p. 8. 
la curva de Lorenz después de impuestos L está más cerca de la línea de equidistribución y estaríamos ante una menor desigualdad de la distribución de la renta. Obsérvese que si el impuesto fuese proporcional, la curva de Lorenz después de impuestos coincidiría con la curva de Lorenz antes de impuestos dado que la curva de Lorenz es invariante ante cambios de escala.

\section{Gráfico 1. Curvas de Lorenz}

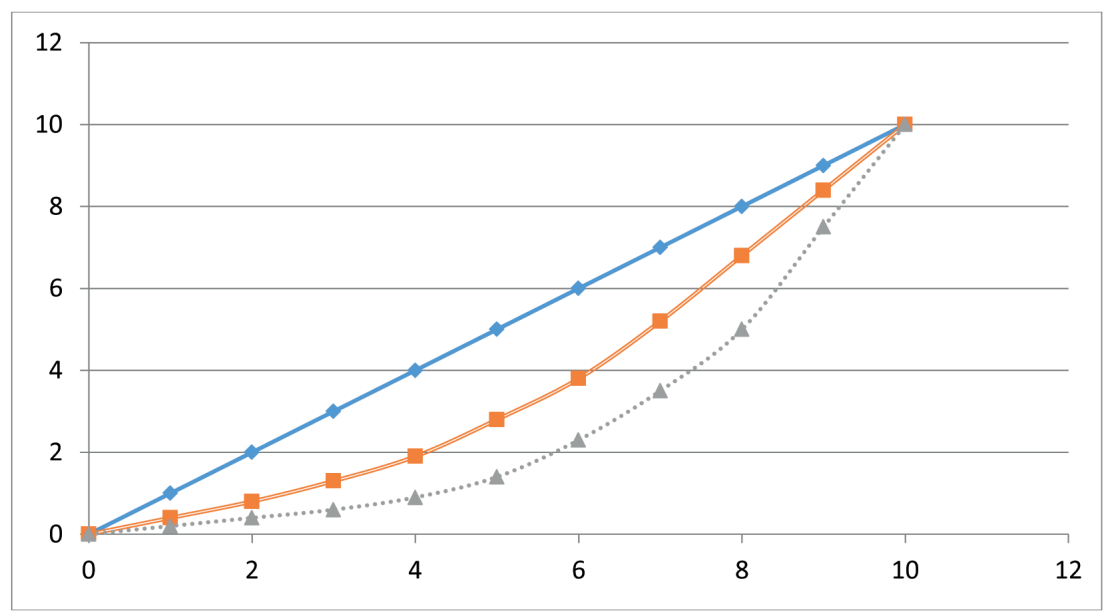

Fuente: Pascual (2004), p. 20.

Esto es, la línea continua en el Gráfico representaría el ideal de que toda la sociedad fuera igualitaria. La curva punteada representa un caso hipotético de la forma de distribución del ingreso de una sociedad. Y la curva con dos rayas representaría el caso de establecer impuestos progresivos que reducen la brecha de la desigualdad al acercarse a la línea continua; como se aprecia, la proporción de desigualdad se reduce a la mitad del área en las curvas. Los coeficientes que miden la desigualdad (como el caso de Gini) miden exactamente las proporciones de dichas áreas antes y después de impuestos. Un impuesto proporcional, en teoría, no introduciría ningún cambio en la curva normal. Por tanto, podría juzgarse en forma empírica el efecto de un impuesto sobre la progresividad o justicia social, tanto si es solo un impuesto o el efecto de todo el sistema fiscal en general, midiendo estas curvas o el grado de acercamiento al ideal de igualdad. Qué tanto debe acercarse al ideal, eso dependería de los valores políticos de la sociedad; la importancia de estos principios es la posibilidad empírica de contar con herramientas que demuestran si los efectos son progresivos o no.

A pesar de los problemas prácticos, Irene Perrote y sus colegas ${ }^{6}$, señalan que los que incorporan diferentes rangos económicos, o nuevas variables para explicar los cambios de riqueza, tienen la ventaja de presentar un reflejo muy importante de los efectos de los impuestos sobre la equidad.

6 Perrote (2003), p. 50. 


\section{Principios fiscales}

Contando ya con los principios genéricos de equidad horizontal y vertical, así como los técnicos relativos a la progresividad y relativos; ahora procederemos a los principios o criterios básicos que tienen como finalidad la forma de repartir la carga fiscal ${ }^{7}$.

a) Benéficios públicos. La idea es que cada persona contribuya o pague impuestos de acuerdo a los beneficios que recibe del estado. Esta propuesta es consistente en teoría bajo los principios de justicia horizontal y vertical. Esto es, puede ser aplicado este criterio a que paguen más los que más tienen lo cual sería en este caso los que más beneficios reciben del estado. Sin embargo, el sistema presenta varios retos en su aplicación.

El primer reto que se plantea consiste en cómo valorar o poner un precio real o justo a todos los servicios que ofrece el estado. Solo en caso de que todos los servicios y programas del estado se ofrecieran como una contraprestación económica (en semejanza al mercado); entonces sería relativamente fácil su aplicación ya que cada quien pagaría conforme fuera adquiriendo lo que necesita. Ideal para un sistema capitalista puro. Sin embargo, al pagar el precio real o de mercado de cada servicio, entonces no se cumpliría el principio de progresividad y se alejaría completamente de los principios sociales de distribución mínima; además de considerar bienes (parques por ejemplo) que por su naturaleza resultan muy difíciles de establecer una cantidad exacta como ya se había adelantado. Además, se plantean como preguntas relativas a la aplicación de este sistema: ¿Quién recibe más del estado? ¿Cómo saberlo? cómo deberían contabilizarse ¿Los programas y servicios sociales bajo este sistema? ¿Cómo establecer costos de los servicios públicos cuando existen no solo diferencias socio-económicas (como ingreso como ejemplo), sino también diferencias socio-territoriales muy marcadas?

b) Consumo o gasto individual. Este principio es similar al anterior, pero se extiende a todo el consumo en general. Consiste en que el que más consume pague más (pudiendo ser un impuesto al consumo como el IVA por ejemplo); como reflejo de la riqueza de las personas. También en teoría puede ser consistente con los principios de equidad horizontal y vertical. Ya que en teoría podría establecerse un sistema progresivo conforme aumenta el consumo; lo cual presenta retos importantes para su aplicación como se verá. Sin embargo, si se aplica a todos los bienes y servicios con la misma tasa, los impuestos al consumo son los más eficientes y de bajo costo de administración, lo que los hace muy atractivos, pero los aleja de la progresividad y equidad. Por ello, frente a los principios de justicia social presenta inconvenientes. En principio, resulta muy difícil hacerlo progresivo, ya que esto lleva a discriminar qué bienes y servicios consumen los ricos y cuáles los pobres. Además, los ricos no dejan de consumir los bienes de los pobres obteniendo con ello un beneficio. El sistema presenta complicaciones al momento de distinguir entre personas fisicas y morales en cuanto al tipo de deducciones o la clasificación del bien que se va a consumir. Así

Pascual y Sarabia (2004), pp. 7-8. 
mismo, al momento de considerar situaciones como la deuda, ahorro o inversión de las personas se complica y favorece a los que más tienen.

c) Ingreso o utilidad de las personas. En este principio se grava de acuerdo a los ingresos (todo tipo de renta como salario, intereses ganados, incremento en valor de acciones y derechos, utilidades, etc.) que obtienen las personas. Es consistente también con los principios de equidad horizontal y vertical, en particular si se establece una tasa progresiva conforme aumentan los ingresos de los contribuyentes ${ }^{8}$.

Aunque presenta mayores ventajas frente al de consumo en cuanto ve a la progresividad, su administración es más onerosa. Los problemas que presenta son la dificultad para establecer un concepto o cálculo de utilidad, junto con el problema de los diferentes tratamientos de las deducciones. Se complica al diferenciar a las personas individuales de las morales, como lo vimos en el tratamiento de utilidad y deducciones lo cual en general favorece a las personas morales y, por tanto, a las personas con mayores recursos económicos que son en última instancia las propietarias de las personas morales.

Además, el tratamiento en el tiempo es otro factor. Debe ser un año, dos o períodos largos. Y, particularmente, si no existe el ingreso se dan discriminaciones importantes, ya sea porque este en verdad no se dio, o por razones del tratamiento fiscal que favorece en ciertas circunstancias que no exista utilidad que gravar. Esto se ejemplifica en el caso de si una persona con un patrimonio muy importante pudiera no tener ingresos en un año; y, al mismo tiempo, una persona de escasos recursos económicos obtiene ingresos ese año (como el caso de la mayoría de trabajadores sujetos a nómina y que están en las posiciones inferiores), dicha persona pagará impuestos y la persona con el patrimonio de importancia no pagará impuesto alguno. Aquí la discusión consistirá en si un patrimonio como tal debe ser gravado o no.

d) Patrimonial. Bajo este principio serían considerados el conjunto de bienes (inmuebles y muebles), ingresos, derechos, regalías, donaciones y similares de una persona. Teóricamente es la definición más completa desde la perspectiva de la justicia social y que en forma consistente considera en toda su amplitud la equidad horizontal y vertical, si es el caso de establecer una tasa progresiva conforme aumenta el patrimonio de las personas. En este caso no afectaría las diferencias en ingresos o cambios (inclusive que no haya ingresos) ya que en última instancia se grava el patrimonio.

Sin embargo, presentaría los mismos problemas que el de ingresos, ya que es forzoso calcular el ingreso por ser uno de los componentes más importantes del patrimonio; además de las complicaciones propias del cálculo de todo el patrimonio en su conjunto. En particular presenta el problema de lo temporal, esto es, el patrimonio al nacer, juventud, mejores años laborales, al finalizar la vida o un promedio. Como en el de ingresos, se complica su cálculo, administración y cobro (lo calcula la persona o el gobierno). Si bien es el más atractivo en la teoría, desde la perspectiva de la justicia 
social, resultaría el más complicado por su costo de aplicación y posibilidades de corrupción por su misma naturaleza.

\section{Análisis Constitucional y legal}

En relación a los principios sobre ética y justicia en materia de ingresos públicos, la Constitución nacional consagra dos principios contenidos en la fracción $\mathrm{V}$, del artículo 31, que establece las obligaciones de los mexicanos; la cual cita:

"V. Contribuir para los gastos públicos, así de la Federación, como de los estados, de la Ciudad de México y del municipio en que residan, de la manera proporcional y equitativa que dispongan las leyes"'.

Sin embargo, la Constitución no ofrece ninguna explicación o indicios que detallen con puntualidad qué es "proporcional y equitativo". Siguiendo la lógica jurídica, dicha conceptualización correspondería a la legislación secundaria. Al respecto, y con el atrevimiento del caso, ninguna legislación secundaria, de cualquiera de los tres niveles de gobierno, en materia de ingresos públicos (impuestos, derechos, etc.) incluye qué debe entenderse por estos principios, los cuales "supuestamente" se deben inferir del diseño de los mismos, correspondiendo a la Jurisprudencia del Poder Judicial de la Federación su definición al resolverse los conflictos en dicha materia.

Cabe señalar que las resoluciones a los amparos promovidos tienen una muy larga historia en relación al litigio fiscal. Lo cual ha ocasionado que los principios en estudio tengan interpretaciones francamente contrarias a lo largo de la historia, principalmente en lo que se refiere a los impuestos sobre ingresos y sobre ventas, los cuales han tenido así mismo cambios significativos desde su base o cobertura fiscal, hasta la forma de las tasas impositivas correspondientes. De esta forma resulta imposible por esta vía definir conceptos claros y permanentes en esta materia tan importante. Sin embargo, se verán las interpretaciones más recientes:

a) Proporcionalidad tributaria. Las personas deben contribuir de acuerdo a su capacidad contributiva, debiendo aportar una parte adecuada de sus ingresos, utilidades, rendimientos o la manifestación de riqueza gravada. En particular los gravámenes deberán ser de tal forma que las personas que obtengan mayores ingresos tributen en forma cualitativamente superior a los de medianos y reducidos recursos. Para que el gravamen sea proporcional debe existir congruencia entre el mismo y la capacidad contributiva de los causantes, entendida esta como la potencialidad real de contribuir al gasto público ${ }^{10}$. 2003. 
b) Capacidad contributiva. Para que un gravamen sea proporcional, se requiere que el hecho imponible del tributo refleje la capacidad económica del sujeto en relación con la potencialidad real de contribuir a los gastos públicos. Esto es, la necesidad de acreditar una estrecha relación entre el hecho imponible y la base gravable a la que se aplica la tasa o tarifa del impuesto ${ }^{11}$.

$\mathrm{Al}$ apreciar estas últimas tesis, y frente a los principios técnicos ya presentados, se aprecia que existe una confusión entre los términos proporcional y progresivo. Por un lado se establece como condición de que paguen más los que más tienen, pero también se hace alusión a los gravámenes que deben ser mayores, lo cual pudiera ser resultado de contar con tasas progresivas. En todo caso, hay que puntualizar que la Constitución proclama el principio de "proporcionalidad" y no el de "progresividad" el cual tiene una mayor connotación de equidad.

Por su parte, la doctrina jurídica en la materia, la cual ha sido fundamental en el desarrollo de las tesis de la Corte, destaca por contar con un poco más de claridad. Margáin Manatou considera que el principio de justicia se traduce en que los habitantes deban contribuir al sostenimiento del gobierno en una proporción lo más cercana posible a sus capacidades económicas. En particular un impuesto es justo y equitativo cuando es general y uniforme. El impuesto es general cuando comprenda a todas las personas cuya situación coincida con la que la señala como hecho generador del crédito fiscal, exceptuando a aquellas personas que demuestren no tener capacidad contributiva ${ }^{12}$. En este aspecto su concepción alude a la equidad horizontal y vertical que ya fue analizada. En este momento tampoco hay claridad si los impuestos o ingresos públicos deberán ser proporcionales o progresivos. Por su parte Ángel Morales, siguiendo los principios constitucionales, desarrolla las siguientes nociones:

a) Principio de Proporcionalidad. Se entiende cuando las leyes impositivas establecen cuotas, tasas o tarifas progresivas que graven a los contribuyentes en función de su capacidad económica es decir, afectar una parte justa y razonable de los ingresos, utilidades o rendimientos obtenidos por cada gobernado individualmente considerado. Este principio se logra mediante el establecimiento de una tarifa progresiva de manera que las personas que obtengan ingresos altos paguen en forma cualitativamente superior a los de medianos y reducidos ingresos, es decir que más grava a quien más gana. Este principio se puede asimilar al Principio de Capacidad Económica que se establece en el sistema tributario español.

b) Principio de Equidad. Tiene por objeto tratar igual a los iguales y desigual a los desiguales. Con esto se logra un tratamiento igualitario a todos los contribuyentes de una misma deuda tributaria, en los nexos jurídicos del nacimiento y elementos de la relación tributaria. La equidad tributaria da certeza a los gobernados que con características exactamente iguales debe diseñarse un esquema para el nacimiento de

11 Véase: Semanario Judicial de la Federación. Jurisprudencia. Tesis P./J. 109/99. Novena Época. X, Noviembre de 1999.

12 Margáin Manatou (1997). 
sus obligaciones, estos en un mismo plano de igualdad y no existe diferencia entre estos, por lo que deben vincularse a los principios de Capacidad Económica. ${ }^{13}$

En este último caso, la interpretación del principio de proporcionalidad, claramente hace alusión al concepto de progresividad al contemplar como forma necesaria el establecimiento de tasas o cuotas progresivas para que en forma efectiva los que más tienen paguen más en términos no solo de cantidad sino de proporcionalidad económica entendida como un índice en el cual los porcentajes de pago son mayores a mayores ingresos. Sin embargo, hay que aclarar que esta última interpretación, la de tasas progresivas, no es compartida por toda la doctrina, ni Jurisprudencia, lo que ocasiona que no exista uniformidad de criterios desde el ámbito del Derecho Público.

\section{Derecho comparado}

\section{Brasil}

Su Constitución destaca por tener un título exclusivo para la tributación o sistema impositivo, así como para las Finanzas Públicas. En relación con el tema que nos ocupa, el título VI de su Constitución contiene diversas disposiciones. En principio, el artículo 145, que establece los principios para los tres niveles de gobierno, señala después de la fracción III, en su inciso $1^{\circ}$., lo siguiente:

"Siempre que fuese posible, los impuestos tendrán carácter personal y se exigirán de acuerdo con la capacidad económica del contribuyente, pudiendo la Administración tributaria, en especial para conferir efectividad a estos objetivos, identificar, respetando los derechos individuales y en los términos de la ley, el patrimonio, los rendimientos y las actividades económicas del contribuyente."

Además, el artículo 150, prohíbe a los niveles de gobierno, en su fracción II, lo siguiente: "dispensar un tratamiento desigual entre contribuyentes que se encontrasen en situación equivalente, prohibiéndose cualquier distinción por razón de ocupación profesional o función por ellos ejercida, independientemente de la denominación jurídica de los rendimientos, títulos o derechos" 14 .

Carlos Peralta al estudiar la Constitución de Brasil, así como su jurisprudencia, señala que el principio de igualdad constituye una medida de proporción y razonabilidad que incide en los demás principios y valores jurídicos, dándoles unidad y coherencia. Señala, en palabras de Ricardo Lobo Torres, el equilibrio y ponderación entre tales principios, resulta la libertad relativa, que no es otra cosa, sino el derecho fundamental al tratamiento impositivo igualitario. Además, Peralta concluye que en materia tributaria, el principio tiene una estrecha relación con el de capacidad contributiva, en tanto presupone que 
existiendo una misma capacidad contributiva con respecto a una determinada manifestación de riqueza, el impuesto deberá ser establecido en iguales términos para todos los contribuyentes en esa situación. De manera que, la capacidad contributiva es en realidad un criterio de aplicación de la igualdad ${ }^{15}$.

A pesar de tales principios constitucionales, las reformas económicas y fiscales han sido marcadas por el principio de eficiencia, como consecuencia de la influencia de organismos internacionales de corte neoliberal en todo Latinoamérica. Al respecto, se encontró que Brasil ha sido el país con mayor presión tributaria en la región, siendo además el que más crecimiento ha experimentado desde 1975. La reforma tributaria emprendida por Lula da Silva en 2003, tras un intento de reformas fallido durante el gobierno de Cardoso entre finales de 1997 y 2000, ha tenido una gran influencia sobre esta evolución fiscal ${ }^{16}$.

\section{Argentina}

El caso de Argentina es muy similar al de México. Se establece en el artículo $4^{\circ}$., dentro de la Primera Parte de su Constitución, en relación a declaraciones, derechos y garantías, la siguiente norma:

"El Gobierno federal provee a los gastos de la Nación con los fondos del Tesoro Nacional, formado del producto de derechos de importación y exportación, del de la venta o locación de tierras de propiedad nacional, de la renta de Correos, de las demás contribuciones que equitativa y proporcionalmente a la población imponga el Congreso General, y de los empréstitos y operaciones de crédito que decrete el mismo Congreso para urgencias de la Nación, o para empresas de utilidad nacional"17.

La Administración Federal de Ingresos Públicos, encargada del cobro de impuestos y demás ingresos públicos, establece que los principios de equidad y proporcionalidad se refieren a que los tributos deben estar de acuerdo con la capacidad contributiva; en correspondencia al patrimonio, a las ganancias y a los consumos de las personas. En se sentido, debe entenderse en el sentido de proporcionalidad en las exteriorizaciones de la capacidad contributiva Es decir, proporcionalmente al capital, a la renta y al consumo; siendo razonable exigir que paguen más los que tienen más renta o mayor patrimonio, respetando los principios de capacidad contributiva. Proporcionalmente al capital, a la renta y al consumo; siendo razonable exigir que paguen más los que tienen más renta o mayor patrimonio, respetando los principios de capacidad contributiva. Teniendo la jurisprudencia en Argentina una trayectoria similar. ${ }^{18}$

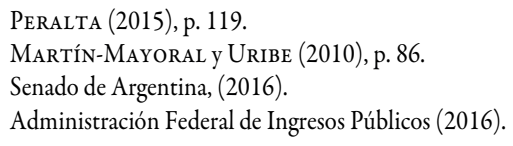




\section{Chile}

Por su parte la Constitución de Chile en su artículo 19, establece criterios similares pero con mayor puntualidad. $\mathrm{Al}$ respecto el numeral $20^{\circ}$., establece:

"La igual repartición de los tributos en proporción a las rentas o en la progresión o forma que fije la ley, y la igual repartición de las demás cargas públicas. En ningún caso la ley podrá establecer tributos manifiestamente desproporcionados o injustos(...)"I9

Además de consagrar el principio ya conocido de igualdad, así como de proporcionalidad, se agrega el término "progresión" como un equivalente del término de proporción. Sin embargo, no ha sido aclarado en forma precisa dicho término o relación entre ambos términos como se verá a continuación.

Fernández González, comentando los principios de la Constitución Chilena, señala que el principio de proporción debe establecerse entre la carga tributaria y los elementos objetivos sobre los que ella recae, o con los cuales se vincula, como la capacidad contributiva del sujeto, el monto, la tasa, el tramo, el porcentaje, la situación del mismo tributo con anterioridad, su tratamiento en el Derecho Comparado y parámetros objetivos. Esto es, la proporcionalidad del tributo se mide en relación con los elementos que se tienen, lo cual es un rasgo cuantitativo más que cualitativo $^{20}$. Además, cita la siguiente jurisprudencia de la Corte Suprema en Chile (28 de enero de 1992):

"Elprincipio de proporcionalidad asegura la debida confianza de que el tributo o gabela que se impongan a los servicios, concesiones o permisos que es la materia que ahora nos interesa guarde la debida relación equitativa, con tales servicios, concesiones o permisos, sobre la base de pautas permanentes e inequivocas, como una forma de respetar el principio básico de igualdad ante la ley e igual repartición de los tributos (... ."21. $^{\text {. }}$.

La dimensión de proporcionalidad en Chile, en el ámbito de la jurisprudencia, se ha visto como un tema de relacionar a la proporcionalidad con la igualdad; como una relación al principio de justicia; como una referencia indirecta a los principios de igualdad horizontal y vertical; o como una relación cuantitativa entre la norma jurídica y el hecho materia del impuesto; además de las cuestiones propias de legalidad. Por lo que se puede apreciar que el término o concepto de "progresión" no ha sido tocado o desarrollado si lo consideramos desde la óptica económica de la progresión en las tasas impositivas, así como sus efectos de que paguen más los que más tienen, pero en un sentido proporcional a su patrimonio y no como una mera cuestión cuantitativa.

\footnotetext{
Cámara de Diputados (2016).

FERNÁNDEZ GONZÁlez (2000), p. 360.

FERNÁNDEZ GoNZÁLEZ (2000), p. 363.
} 


\section{Situación fiscal en México}

En relación, a México con el sistema fiscal ha transitado hacia una simplificación o reducción de tipos de impuestos, así como una homogenización mediante el Sistema Nacional de Coordinación Fiscal. En relación con el Impuesto Sobre la Renta (ISR), el antecedente se encuentra en la Ley del 20 de junio de 1921, que estableció el Impuesto del Centenario en forma transitoria. Posteriormente, la Ley del 21 de febrero de 1924 lo establece en forma permanente, teniendo reformas en 1953, 1964, 1980, 1991, etcétera. En cuanto al Impuesto al Valor Agregado (IVA) o impuesto sobre ventas, el antecedente corresponde al Impuesto Federal Sobre Ingresos Mercantiles (ISIM), implantado en el año de 1948, cuyo propósito fue sustituir el Impuesto General del Timbre que resultaba obsoleto para gravar el comercio y la industria. El impuesto contempló inicialmente una sola tasa del $3 \%$ en 1971 , incorporándose la tasa especial del $10 \%$ a productos no necesarios. En 1973 se adoptó la tasa del 4\% y en 1974 se incorporaron las tasas del 5\%, 15\% y $30 \%$ para automóviles. Finalmente en 1978 se incluyó la tasa del $7 \%{ }^{22}$.

En 1980 se dio una de las reformas de mayor impacto al promulgarse la Ley de Coordinación Fiscal que crea el Sistema Nacional respectivo por medio del cual se han suprimido una variedad de impuestos e ingresos estatales y municipales, a cambio de fondos federales; así como reformas al ISR y la creación del Impuesto al Valor Agregado. Respecto de la década de los ochentas, debido a la crisis económica heredada, así como las políticas macroeconómicas y neoliberales para ajustar las finanzas públicas, en términos fiscales no se dieron cambios importantes al régimen. Siendo hasta la administración del presidente Ernesto Zedillo (1994 - 2000) que se retoman reformas en la materia. Se otorgó autonomía técnica al Sistema de Administración Tributaria (SAT) en 1997, con lo cual se inicia una mayor profesionalización y eficiencia en la recaudación. Además, se aumentó la tasa del IVA del 10\% al 15\%. Sin embargo, la recaudación tributaria disminuye, compensándose con los ingresos al petróleo.

En términos económicos el sistema tributario en México es ineficiente. Los ingresos tributarios, sin contar los ingresos del petróleo, representaron 10.6\% del Producto Interno Bruto (PIB) en promedio para el periodo de 1977-2003. El ISR representó el impuesto más importante (ver tabla 1). Respecto del IVA, su productividad fue de 22.7\% para dicho período. Esto es, de cada 100 pesos que potencialmente podrían ser recaudados solo se recaudaron 23 pesos. Esto en razón de las diferentes tasas y el amplio régimen de exenciones. El ISR presenta un caso similar al presentar una cantidad considerable de tratamientos especiales y exenciones poco justificadas. Cantalá menciona que en el caso del ISR dirigido a personas físicas, las exenciones y los tratamientos especiales no solo reducen la recaudación potencial, sino que también complican y dificultan la actividad recaudatoria; además del problema de la evasión ${ }^{23}$.

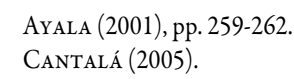


Tabla 1. Datos fiscales comparativos

\begin{tabular}{|c|c|c|c|}
\hline \multicolumn{2}{|c|}{ México, 1977 - 2003} & & \\
\hline ISR & $44 \%$ & & \\
\hline IVA & $28 \%$ & & \\
\hline IEPS & $17 \%$ & & \\
\hline Otros & $11 \%$ & & \\
\hline$\%$ PIB & $10,60 \%$ & & \\
\hline \multicolumn{4}{|l|}{ 2003-2005 } \\
\hline \multicolumn{2}{|l|}{$\%$ PIB } & \multicolumn{2}{|c|}{ \% ISR Empresarial } \\
\hline OCDE & $25,1 \%$ & Argentina & $35 \%$ \\
\hline Brasil & 17,3 & Colombia & $35 \%$ \\
\hline Argentina & $15,50 \%$ & OCDE & $28 \%$ \\
\hline Colombia & $13,50 \%$ & México & $28 \%$ \\
\hline México & $9,70 \%$ & Brasil & $15 \%$ \\
\hline
\end{tabular}

Fuente: Álvarez Estrada (2009).

$\mathrm{Al}$ inicio de la década de este nuevo mileno, la eficiencia tributaria se reduce aun más, al bajar al 9.7\% del PIB para el período 2003 al 2005. Al realizar un breve comparativo internacional, México no sólo recauda poco en términos del PIB, sino que además presenta tasas impositivas bajas al referirse a los topes máximos del ISR; inclusive en comparación con Latinoamérica. La tendencia histórica del ISR en México ha consistido en una disminución de tasas para homologarse al entorno internacional de países desarrollados ${ }^{24}$.

México ha presentado un entorno de tasas competitivas, pero una baja recaudación derivada de los problemas ya citados de una base fiscal reducida, así como los regímenes especiales y de deducciones. En consecuencia, la finalidad de las reformas fiscales al inicio del nuevo milenio ha consistido en mejorar la eficiencia recaudatoria y sortear los problemas económicos. En particular el presidente Fox (2000 - 2006) introdujo el Impuesto al Activo en 2002. Se logra la reducción de la tasa máxima del ISR para personas físicas de 40\% a 35\%; y 32\% para físicas y morales en 2005. Además, el IVA se modificó al causarse sobre flujos de efectivo.

Ya en el sexenio de Calderón (2006 - 2012) se continuó como política principal la de aumentar la base fiscal. Al efecto se crea el Impuesto Empresarial a Tasa Única (IETU), el cual se causaba sobre flujos de efectivo, sustituyendo al IMPAC, esto en 2008. Este Impuesto fue abrogado con la reforma de diciembre del 2013. Para 2010, se aprobó el alza en un punto porcentual del IVA al 16\% y al ISR en dos puntos para llegar al 30\%. Asimismo, se incluyó un nuevo impuesto del 3\% sobre algunos servicios de telecomunicaciones. Para incentivar la tributación, se estableció un nuevo programa tributario para pequeñas y medianas empresas facilitando la tramitación electrónica de impuestos.

24 Álvarez Estrada (2009), pp. 13-16. 
El presidente Peña Nieto (2012 - 2018) mandó su reforma fiscal en septiembre del 2013 con la finalidad de eficientar los impuestos. Entre los puntos aprobados para el 2014 destacaron: la eliminación del IDE (depósitos en efectivo) y el IETU.; tasa del 16\% en IVA en la frontera; desaparición del Régimen de Pequeños Contribuyentes y aparición del Régimen de Incorporación Fiscal para personas físicas con actividad empresarial e ingresos menores a 2 millones de pesos; se limitó la deducción de previsión social para los patrones en un 47\%; despareció el Régimen Simplificado y se crearon capítulos especiales para agricultores, ganaderos y pescadores; los dividendos tendrán una pago de ISR definitivo del 10\%; los ingresos por ganancias en bolsa pagarán ISR del 10\%; desapareció el régimen de consolidación fiscal; y se grava con el IEPS los alimentos no básicos ${ }^{25}$.

\section{Aproximación teórico empírica a la equidad fiscal}

\section{Problemática y desarrollo teórico}

El presente estudio inició con la interrogante de si la Ciencia Jurídica, así como el Derecho Positivo vigente, ha definido o desarrollado en forma puntual los principios de equidad fiscal, en particular el concepto de "proporcionalidad". El marco teórico, basado en la Filosofía y Economía, demostró que no existe una sola respuesta en atención a los principios morales o enfoques que existan sobre justicia y equidad. Por ejemplo, para unos un sistema fiscal será justo cuando todos paguen lo mismo y tengan garantizado el acceso a un mercado libre (postura clásica liberal y capitalista). En otros casos, el pago de impuestos será justo cuando paguen más los que más tienen (postura relativa a la justicia social o socialismo). En este último caso, quedaría todavía por definir qué es pagar más o qué es encontrarse en una situación patrimonial o económica similar.

Sin embargo, si existen una serie de principios económicos congruentes que dan sustento y medición a la forma de comprender la equidad fiscal, esto es, qué es que paguen más los que más tienen, y qué es una misma situación económica o fiscal. Siendo los puntos teóricos más sobresalientes los siguientes:

a. Un impuesto o sistema fiscal es totalmente eficiente cuando no hay diferencia entre un impuesto que no genera distorsión en los precios de los bienes y la carga obtenida vía la disminución del ingreso de las personas. Por ejemplo, un impuesto universal a los individuos o al patrimonio (misma tasa a todos); o un impuesto con la misma tasa a todos los bienes y servicios de la economía.

b. Desde la óptica de equidad, basada en el principio de que paguen más los que más tienen (justicia vertical y horizontal), el arreglo antes citado sería injusto en razón de que todos pagarían la misma cantidad y, además, pudiera ser regresivo (paguen más los que menos tienen) si se considera el análisis de lo pagado frente al patrimonio personal. 
c. Por lo tanto, la forma de medir la equidad vertical y horizontal consiste en verificar lo que se paga frente al patrimonio; y no considerar lo que se paga en cantidad. Por tanto, un impuesto solo será equitativo y justo, cuando pagan más los que más tienen en términos proporcionales o de su patrimonio. Esto quiere decir que a mayores ingresos o patrimonio, deberán pagar mayores proporciones (\%) de dichas bases fiscales. Situación que se le denomina "progresividad", medida no solo en que el pago o cantidad en efectivo sea mayor, sino en términos proporcionales.

d. En el caso de que se pague lo mismo, en términos proporcionales, el impuesto será "proporcional" o neutral; y en caso de que los que menos tienen, paguen más (lo cual sucede por lo general en los impuestos sobre ventas), el impuesto será regresivo. Desde esta óptica técnica, los impuestos se pueden diseñar desde un punto de vista de eficiencia (para generar menos costos a la economía) o desde una óptica de equidad vertical u horizontal.

\section{Resultados empíricos}

México se ha caracterizado por ser un país con poca carga fiscal o tributación muy baja de acuerdo a los niveles internacionales y en comparación de las naciones hermanas en Latinoamérica. En razón de esa situación, las reformas fiscales en los últimos años han venido orientadas bajo la premisa de eficiencia y aumentar los recursos fiscales, como estrategia para fortalecer las finanzas públicas e ir disminuyendo la dependencia sobre los ingresos del petróleo.

Ejemplo de esto lo vemos en las reformas desde inicios del presente siglo. Se crean impuestos como el del Activo, el Empresarial a Tasa Única, aumentos en la tasa del Impuesto al Valor Agregado (ventas), desaparición del régimen de pequeños contribuyentes, se gravan nuevos productos como alimentos no básicos, limitaciones a deducciones, eliminación de régimen simplificado, entre otros. En forma clara, desde su diseño, al tener tasas únicas, gravar consumo y demás características, se aprecia que la intención de la reforma es aumentar los ingresos sin importar que el efecto económico sea proporcional o regresivo.

Esta situación se confirma con otros estudios en la materia que confirman la orientación de eficiencia y no de equidad de las reformas ${ }^{26}$. Además, Daniel Álvarez encontró los siguientes problemas tanto de recaudación como de regresividad: los impuestos patrimoniales en México representan menos del 2\% de la recaudación nacional, ejemplificado por la subutilización del impuesto predial; el impuesto sobre la renta presenta serias deficiencias en su diseño al tener amplios tratamientos preferenciales para sectores completos de contribuyentes, existen fuentes de ingresos que gozan de tratamientos especiales tanto para personas físicas como morales; además la aplicación del crédito al salario ha incentivado una elasticidad-ingreso negativa del impuesto con relación al PIB ${ }^{27}$.

Huesca y Serrano (2005), p. 119.

Álvarez (2009), p. 50-51. 
Situación similar se reproduce en Latinoamérica con las reformas que se imponen desde organismos internacionales en las cuales se privilegia la eficiencia sobre la equidad en las reformas tributarias ${ }^{28}$.

\section{Consideraciones finales}

Conforme a los puntos anteriores, se demostró que los conceptos económicos y técnicos de regresividad, proporcionalidad y progresividad no coinciden plenamente en el ámbito del Derecho Público. En el caso de México la Constitución señala, sin definir, que los impuestos deberán ser equitativos y proporcionales. En el ámbito de la jurisprudencia, la proporcionalidad se ha definido como la característica por la cual las personas contribuyen de acuerdo a su capacidad contributiva, debiendo aportar una parte adecuada de sus ingresos, utilidades, rendimientos o la manifestación de riqueza gravada. En particular los gravámenes deberán ser de tal forma que las personas que obtengan mayores ingresos tributen en forma cualitativamente superior a los de medianos y reducidos recursos. Para que el gravamen sea proporcional debe existir congruencia entre el mismo y la capacidad contributiva de los causantes.

Inicialmente parece claro el principio vertical de que paguen más los que más tienen. Situación que se infiere de que los gravámenes sean de tal forma que las personas de mayores ingresos tributen en forma cualitativamente superior a los de medianos y reducidos recursos. La palabra gravamen se refiere al impuesto en sí o al pago; no se refiere a que la tasa sea progresiva o no. Y, cualitativamente superior pudiera interpretarse tanto en términos absolutos de cantidad, como en términos de proporción al pago mismo o, como en términos de proporción del pago frente al patrimonio de las personas. Por tanto, al ser un concepto o frase genérica, bajo estas condiciones de legalidad, pudiera aprobarse como constitucional un impuesto, o dos, que al mismo tiempo sean "proporcional" o "progresivos" en sus tasas o cuotas. En ambos casos, "se da un gravamen cualitativamente superior". En el primer caso se paga más en términos de cantidad o absolutos y, en el segundo caso, se paga más en términos proporcionales frente a la transacción económica o patrimonio de la persona. Bajo la perspectiva del Derecho Público en México, ambos conceptos de proporcional y progresivo son equitativos y así han sido utilizados por la jurisprudencia. Sin embargo, desde la perspectiva de la Microeconomía, el caso de proporcional es neutral y el segundo referido a la progresividad corresponde al de equidad.

En el caso de Brasil se distingue por los principios constitucionales de que el impuesto deberá ser de acuerdo a la capacidad económica del contribuyente; así como la prohibición de dispensar un tratamiento desigual entre los contribuyentes. De esta forma el régimen jurídico reconoce los principios de tributación ya comentados (equidad vertical y horizontal) pero, al igual que en México, la jurisprudencia no llega al detalle o precisión de definir dicha equidad en relación al tipo de tasas, quedando de nueva cuenta el uso del

28 Uribe (2006), p. 52-53. y Clavijo (2011), p. 65. 
concepto genérico de proporcionalidad. En cuanto a Argentina su Constitución reproduce los mismos principios que en el caso mexicano, esto es, que las contribuciones sean equitativas y proporcionales. Sin embargo, su jurisprudencia se acerca más a los conceptos económicos al señalar que la capacidad contributiva será en proporción al capital, a la renta y al consumo, siendo razonable exigir que paguen más los que más tienen renta o mayor patrimonio. A pesar de este adelanto, en la práctica la Corte Argentina sigue declarando constitucionales impuestos con tasa única. Por lo cual, bajo la última perspectiva (proporción en razón al consumo) los impuestos proporcionales y progresivos tienen la misma connotación.

La Constitución de Chile se distingue del resto al señalar en forma clara que los tributos serán “en proporción a las rentas o en la progresión o forma que fije la ley”. A pesar de haber incluido el concepto de progresión (el cual pudiera ser fundamental en el desarrollo de la jurisprudencia), las tesis en Chile siguen los mismos desarrollos relativos al concepto de "proporcionalidad", sin hacer una distinción clara entre los conceptos técnicos de proporción y progresividad de las tasas como argumentos para distinguir si un impuesto tienen equidad o no.

Como se acredita, desde el ámbito del Derecho Público no existe claridad en cuanto al principio de equidad aplicado en relación al concepto constitucional de proporcionalidad. Se le utiliza en forma indistinta para definir una situación en la cual el impuesto o gravamen puede ser en sus tasas proporcional o progresivo, sin importar que se refiera a que paguen más en términos de cantidad, proporcionales frente a la venta, ingresos o patrimonio. En términos estrictamente económicos, la equidad, medida en razón del principio vertical, se da cuando la tasa es progresiva y se paga más en proporción al pago frente al patrimonio de las personas. En todo caso, es tarea para el Derecho, desde el ámbito Constitucional y Fiscal, definir en forma clara cuál principio fiscal debe operar en la práctica. Si debe prevalecer un criterio de eficiencia o de equidad y así dar congruencia a todo el sistema fiscal. En caso de que fuera el de equidad, entonces el concepto constitucional que debe garantizarse debe ser el de "Progresividad" y aplicarse los principios fiscales siguientes, para todo tipo de autoridad y jueces en la materia:

a. Establecer tasas o cuotas que aumenten por escalas o rangos de capacidad económica. Entre más rangos existan en las tasas, más progresivo será el impuesto.

b. Los impuestos patrimoniales (predial e ingresos) son los mejores candidatos para asegurar la progresividad del sistema.

c. Los regímenes especiales y de deducciones deben ser equitativos, en todo caso, no conceder mayores beneficios a los de posiciones económicas más altas ya que reduce la tasa efectiva o progresividad del impuesto.

d. No hacer distinciones en el régimen de deducciones y demás incentivos fiscales entre personas físicas y morales; en todo caso, asegurarse de gravar en forma progresiva y eficiente a las personas físicas que son dueñas o participan de las ganancias de las personas morales. 
e. Los impuestos al consumo no deben ser de tasa única; ya que su efecto es proporcional en algunos segmentos de la población y regresivo para las clases bajas. En todo caso, deberá presentar al menos cierto rango de tasas (en atención al tipo de producto) para asegurar un mínimo de progresividad.

f. Los impuestos indirectos, como especie de impuesto al consumo (tenencia o placas vehiculares, cigarros, alcohol, hospedaje, etc.), pueden tener tasas progresivas y aumentan la progresividad general del sistema ya que su consumo está ligado al consumo de clases medias y altas.

g. Los ingresos fiscales como derechos, aprovechamientos, aportaciones, licencias (e inclusive multas), también pueden diseñarse en forma progresiva con base en criterios geográficos o tipo de servicio público.

La equidad, medida como un sistema con impuestos de tasa progresiva, no implica que la recaudación fiscal sea menor. Ya que es posible diseñar un régimen donde se amplía en forma efectiva la base fiscal, obteniéndose los recursos vía la ampliación de la base y de los ingresos o pagos de las tasas mayores.

\section{Referencias bibliográficas}

Álvarez Estrada, Daniel (2009): “Tributación directa en América Latina: equidad y desafíos. Estudio del caso en México”, en: Serie Macroeconomía del Desarrollo, 91, CEPAL, Santiago de Chile.

Administración Federal de Ingresos Públicos (2016), Principios Constitucionales en Materia Tributaria, Buenos Aires, 20 de julio. Disponible en: http://www. afip.gov.ar/institucional/afipSimulada/archivos/Principios\%20constitucionales\%20 en\%20materia\%20tributaria.pdf

Auerbach, Alan J. (1985): "The Theory of Excess Burden and Optimal Taxation”, en: Handbook of Public Economics, Vol I., North-Holland, Amsterdam, pp. 61-127.

Ayala, J. (2001): Economía del Sector Público Mexicano, 2a ed., Esfinge, México.

Clavijo, Sergio (2011): Estructura Fiscal de Colombia y Ajustes Requeridos (20102020), Fedesarrollo, Centro de Investigación Económica y Social, Bogotá, 10 de marzo del 2016. Disponible en: http://www.repository.fedesarrollo.org.co/ handle/11445/321.

Cámara de Diputados (2016): Constitución de la República de Chile, Santiago de Chile, 4 de agosto 2016, en: https://www.camara.cl/camara/media/docs/constitucion_politica.pdf.

CAntalá, D., et al. (2005): Evasión Fiscal en el Impuesto sobre la Renta de Personas Físicas, El Colegio de México, México, 10 de febrero 2016. Disponible en: ftp://ftp2. sat.gob.mx/asistencia_servicio_ftp/publicaciones/estudios_ef/EvFiIsrP-FAr06.pdf. 
Fernández González, Miguel Ángel (2000): "Principios Constitucionales de Proporcionalidad y Justicia en Materia Tributaria”, en: Revista Chilena de Derecho, vol. 27 No. 2, pp. 357-371.

Huesca, Luis y Serrano, Alfredo (2005): "El impacto fiscal redistributivo desagregado del impuesto al valor agregado en México: vías de reforma”, en: Investigación Económica, vol. LXIV, 253, Facultad de Economía, México, julio-septiembre, pp. 89-122.

INEGI (2015): Anuario Estadístico y Geográfico de los Estados Unidos Mexicanos 2015, Aguascalientes, 4 de abril 2016. Disponible en: http://www3.inegi.org.mx/sistemas/ biblioteca/ficha.aspx?upc=702825077280.

Lobaiza, María Lorena (2001): Presión Tributaria del Impuesto al Valor Agregado Bajo distintos Indicadores de Bienestar, Documento de Trabajo No. 39, Universidad Nacional de la Plata, Buenos Aires.

Margáin Manatou, E. (1997): Introducción al Estudio del Derecho Tributario Mexicano, Porrúa, México.

Martín-Mayoral, Fernando y Uribe, Carlos Andrés (2010): "Determinantes económicos e institucionales del esfuerzo fiscal en América Latina”, en: Investigación Económica, Vol. 69, no. 273, UNAM, México, julio-septiembre, pp. 85-113.

MGI (2015): Resumen Ejecutivo de Reforma Fiscal 2014, México, pp. 3-4, 23 de abril 2016. Disponible en: http://www.mgimexico.com/v3/images/pdf/reformafiscal2014.pdf

Morales Velueta, Ángel (2014): “Los Derechos en el Sistema Tributario Mexicano”, en: Perfiles de las Ciencias Sociales, Año 2, Núm. 3, Julio-Diciembre, UJAT, México, pp. 45-54.

Musgrave, Richard A. (1990): "Horizontal Equity once more", en: National Tax Journal, 43, pp. 113-22.

Norman, Ireland J. (1998): “Status seeking, income taxation and efficiency”, en: Journal of Public Economics, 70, pp. 99-113.

Nozick, Robert (1974): Anarchy, State and Utopia, Basic Books, New York.

Pascual, Marta y Sarabia, José María (2004): La Medición de la Equidad en la Implementación de los Sistemas Impositivos, Universidad de Cantabria e Instituto de Estudios Fiscales, Santander.

Peralta, Carlos (2015), “Tributación y Derechos Fundamentales. Reflexiones a partir de los ordenamientos jurídicos de Brasil y Costa Rica”, en: Revista de Ciencias Jurídicas, No. 138, septiembre-diciembre, Universidad de Costa Rica, pp. 89-134.

Raw LS, John (1971): A Theory of Justice, Harvard University Press, Cambridge.

Senado de Argentina, (2016): Constitución de Argentina, Buenos Aires, 26 de Julio de 2016, en: http://www.senado.gov.ar/Constitucion/capitulol.

Supremo Tribunal Federal (2016): Constitución de Brasil, Brasilia, 20 de julio de 2016, en: http://pdba.georgetown.edu/Constitutions/Brazil/tituloVI.html. 
URIBE URIBE, Rafael (2006): “Una reforma tributaria neoliberal regresiva”, en: Revista Ciencias Estratégicas, Vol. 14, No. 15, Medellín Colombia, Ene-Jun, pp. 47-58.

ZeE, Howell H. (1995): “Taxation and Efficiency”, en: Tax Policy Handbook, International Monetary Fund, Washington D.C., pp. 25-34. 